\title{
Expression of Somatostatin Receptors 1-5 and Dopamine Receptor 2 in Lung Carcinoids: Implications for a Therapeutic Role
}

\author{
George Kanakis $^{a} \quad$ Lars Grimelius $^{\mathrm{e}}$ Athanasios Spathis ${ }^{\mathrm{b}}$ Rodoula Tringidou ${ }^{\mathrm{c}}$ \\ George Z. Rassidakis ${ }^{d}$ Kjell Öberg ${ }^{f}$ Gregory Kaltsas $^{a} \quad$ Apostolos V. Tsolakis $^{f}$ \\ ${ }^{a}$ Endocrine Unit, Department of Pathophysiology, University of Athens Medical School, ${ }^{b}$ Division of Cell Biology, \\ Center of Basic Research, Biomedical Research Foundation Academy of Athens, 'Department of Pathology, 'Sotiria' \\ Chest Diseases Hospital of Athens, and d First Department of Pathology, National and Kapodistrian University of \\ Athens, Athens, Greece; e Institution of Immunology, Genetics and Pathology and ${ }^{\mathrm{f}}$ Department of Medical Sciences, \\ Uppsala University, Uppsala, Sweden
}

\section{Key Words}

Somatostatin receptor subtypes - Dopamine receptor 2 . Immunohistochemistry · Lung carcinoids

\section{Abstract \\ Objective: The expression of somatostatin receptors (SSTRs) and dopamine receptor 2 (DR2) in neuroendocrine tumors is of clinical importance as somatostatin analogues and dopa- mine agonists can be used for their localization and/or treat- ment. The objective of this study is to examine the expres- sion of the five SSTR subtypes and DR2 in lung carcinoids (LCS). Methods: We conducted a retrospective study of 119 LCs from 106 patients [typical carcinoids (TCs): $n=100$, and atypical carcinoids (ACs): $n=19]$. The expression of all five SSTR subtypes and DR2 was evaluated immunohistochemi- cally and correlated to clinicopathological data. In a sub- group of cases, receptor expression was further analyzed us- ing semiquantitative RT-PCR. Results: SSTR2A was the SSTR subtype most frequently expressed immunohistochemical- ly (72\%), followed by SSTR1 (63\%), SSTR5 (40\%), and SSTR3 (20\%), whereas SSTR4 was negative. DR2 was expressed in $74 \%$ and co-expressed with SSTR1 in 56\%, with SSTR2A}

in 59\%, with SSTR3 in 19\%, and with SSTR5 in 37\% of the tumors. Receptor expression was not related to the histological subtype, tumor aggressiveness (disease extent/grading) or functionality; however, DR2 was expressed more frequently in ACs than TCs (95 vs. $70 \%, p=0.017$ ). In a subset of patients, RT-PCR findings highly suggested that the expression of SSTR2A, SSTR3, DR2, and to a lesser extent that of SSTR1 and SSTR5 is the outcome of increased gene transcription. Conclusions: The high and variable immunohistochemical expression of the majority of SSTRs along with their co-expression with DR2 in LCs provides a rationale for their possible treatment with agents that target these receptors.

(c) 2015 S. Karger AG, Basel

\section{Introduction}

The respiratory tract comprises one of the most common primary locations of neuroendocrine tumors (NETs; $20-30 \%)$ that have an incidence of 1.35 cases per 100,000 inhabitants $[1,2]$. NETs of the respiratory tract are divided into well-differentiated (lung carcinoids, LCs) and poorly differentiated endocrine carcinomas (PDECs).

\section{KARGER 125}

() 2015 S. Karger AG, Base

0028-3835/15/1013-0211\$39.50/0

E-Mail karger@karger.com

www.karger.com/nen
Apostolos V. Tsolakis

Section of Endocrine Oncology, Department of Medical Sciences, Uppsala University Uppsala University Hospital, Entrance 70, 3rd Floor, Research Department 2 SE-751 85 Uppsala (Sweden)

E-Mail apobtsol@ hotmail.com 
According to the WHO 2004 classification, LCs are further subdivided into typical carcinoids (TCs) and atypical carcinoids (ACs). TCs are characterized by $<2$ mitoses/10 high-power fields (HPF) and the absence of necrosis, whereas ACs are defined by $2-10$ mitoses/ $10 \mathrm{HPF}$ and/ or the presence of necrosis. PDECs are distinguished by the presence of $>10$ mitoses $/ 10 \mathrm{HPF}$ and necroses and are subdivided further into large-cell neuroendocrine carcinomas (LCNEC) and small-cell lung carcinomas (SCLC) according to their morphological features $[3,4]$.

Somatostatin receptor (SSTR) expression is of importance in the diagnosis and management of patients with NETs. The SSTR subtypes 1-5 are targeted via somatostatin receptor scintigraphy (SRS) and long-acting somatostatin analogues (SAs) $[5,6]$ and/or peptide receptor radionuclide treatment [7] for diagnostic and therapeutic purposes, respectively. To date, only a limited number of studies have demonstrated the expression of SSTR subtypes other than SSTR2A in NETs with divergent results, possibly due to differences in the methodology applied [8-18]. Data concerning LCs are even more sparse and inconsistent $[15,18-23]$. Among the five subtypes of SSTRs, SSTR2A is the one most frequently expressed, exhibiting mainly membranous immunostaining, while the other subtypes present mainly cytoplasmic expression [24]. Recently, the precise expression of SSTRs in NETs has become more relevant as newer SAs with an affinity to multiple SSTRs have become available [25].

Five dopamine receptor (DR) subtypes have been cloned and they are divided further into D1-like and D2like. Among DRs, DR2 is of particular importance since it is the main target for dopamine agonists (DAs) [26]. This receptor exists in two isoforms: D2-long and D2short and is expressed in a variety of NETs. There is evidence to suggest a synergistic action between SAs and DAs in controlling hormonal secretion from functioning NETs [27]. This may be attributed to heterodimerization between SSTRs and DRs that result in new oligomeric receptor entities with enhanced functional activity [28]. To date, only few studies have investigated the expression of DR2 in NETs, and only two included a small number of LCs [11, 29-32]. In addition, the co-expression of SSTRs and DRs has not been examined in LCs.

The purpose of this study is to investigate the expression of the five SSTR subtypes along with DR2 in LCs by means of immunohistochemistry (IHC) and compare their expression to real-time polymerase chain reaction (RT-PCR) and SRS findings of the same patients in order to provide a rationale for possible treatment with agents that target these receptors.

\section{Materials and Methods}

\section{Patients and Tumors}

This study included 119 primary LC tumors as well as lymph node $(\mathrm{n}=11)$ and distant metastases $(\mathrm{n}=6)$ derived from $106 \mathrm{pa}$ tients (63 females, 59\%) from three institutions. Six patients harbored two tumors, whereas in 3 patients, the disease consisted of multiple tumorlets. The mean age at diagnosis was $52.0 \pm 15.4$ years (range 16-82). In 2 patients, LCs emerged in the context of multiple endocrine neoplasia 1 (MEN 1) syndrome. Six patients had received chemotherapy and/or biotherapy preoperatively: paraplatin and vepecid $(n=1)$, temozolomide $(n=3)$ and interferon- $\alpha(n=2)$. Two patients had received SAs in the context of carcinoid syndrome.

According to the WHO 2004 criteria, the tumors were classified as TCs $(\mathrm{n}=100)$ and ACs $(\mathrm{n}=19)$. The mean primary tumor diameter was $22.3 \pm 12.4 \mathrm{~mm}$. Six patients presented with symptoms of hormonal hypersecretion (functioning tumors); 3 with Cushing's syndrome due to ectopic adrenocorticotrophin secretion, and 2 with typical and 1 with atypical carcinoid syndrome. At the time of diagnosis, 19 patients $(21 \%$; 13 TCs and 6 ACs) had lymph node involvement, whereas 12 patients (11\%; 6 TCs and 6 ACs) had distant metastases. No significant difference was observed between TCs and ACs regarding patients' sex, age at initial diagnosis and functional status, whereas ACs had a significantly larger mean tumor size (table 1). For comparison reasons, the expression of the five SSTRs and DR2 were also studied in 20 PDECs: biopsy material of 12 SCLCs (10 pure and 2 combined with LCNEC) and 8 LCNECs (surgical material).

SRS data (obtained prior to tumor excision) were available in 18 patients. In 16 cases, SRS with 175-220 MBq 111In-DTPAoctreotide was performed, and the results were evaluated $24 \mathrm{~h}$ after administration, according to Krenning's scale (KS; $0=$ no abnormality; 1 = faint uptake in the tumor; 2 = clear uptake in the tumor but less than in the liver; 3 = uptake greater in the tumor than in the liver, and $4=$ uptake much greater in the tumor than in the liver) [33]. In 2 cases, where only 68Ga-DOTATOC PET scan was available, a SUV $\max >5.5$ was considered as positive.

\section{Controls}

Macroscopically normal pancreatic tissue from 1 patient operated for a pancreatic NET was used as the 'positive' control for SSTRs. Normal adenohypophysis tissue obtained post-mortem as well as pituitary adenomas with documented response to DA were used as 'positive' controls for DR2. Normal human tonsil was used as the 'positive' control for the Ki67 labeling index (LI). 'Negative' immunostaining controls included omission of the primary antisera and replacement of the primary antibody by nonimmune serum at the same dilution as the primary antibody in question and in the same diluent. In occasional cases, a neutralization test was conducted following a 24-hour incubation of primary antiserum with the relevant antigen $(10 \mathrm{nmol}$ antigen per milliliter diluted antibody solution) before application to the sections. The SSTRs antigens used were from Gramsch Laboratories (Schwabhausen, Germany): SSTR1 (SS-841); SSTR2A (SS-801); SSTR3 (SS-851); SSTR4 (SS-881), and SSTR5 (SS-891) as well as from Epitomics Inc. (Burlingame, Calif., USA): SSTR2 (P-3582-1); the antigen for DR2 (NLS1403PEP) was from Novus Biologicals (Littleton, Colo., USA). 
Table 1. Clinicopathological data of the cohort of 106 patients with LCs, overall and stratified according to tumor histology

\begin{tabular}{lccccc}
\hline & $\begin{array}{l}\text { Overall } \\
(\mathrm{n}=106)\end{array}$ & $\begin{array}{l}\text { TCs } \\
(\mathrm{n}=91)\end{array}$ & $\begin{array}{l}\text { ACs } \\
(\mathrm{n}=15)\end{array}$ & $\chi^{2}(\mathrm{t})$ & $\mathrm{p}$ \\
\hline Sex, female/male & $63 / 43$ & $53 / 38$ & $10 / 5$ & 0.379 & 0.585 \\
Age at diagnosis, years & $52.0 \pm 15.4$ & $52.0 \pm 14.7$ & $51.4 \pm 19.7$ & $(0.150)$ & 0.881 \\
Size of primary tumor, mm & $22.3 \pm 12.4$ & $21.0 \pm 11.2$ & $30.3 \pm 16.1$ & $(2.777)$ & 0.007 \\
Functional status & $6(5.7)$ & $4(4.4)$ & $2(13.3)$ & 2.881 & 0.155 \\
Lymph node involvement & $19(21)$ & $13(14)$ & $6(40)$ & 5.543 & 0.029 \\
Distant metastases & $12(11)$ & $6(7)$ & $6(40)$ & 12.090 & 0.003 \\
\hline
\end{tabular}

Values are presented as \pm SD or $\mathrm{n}(\%)$ unless otherwise indicated.

\section{Immunohistochemistry}

The neuroendocrine differentiation of the tumors was confirmed by routine immunostaining with the general neuroendocrine markers chromogranin A and synaptophysin. Immunostaining was applied using a polymer detection system (Dako Cytomation, EnVision ${ }^{\circledR}+$ System-HRP, K4010). The Dako Autostainer was used for the routine immunostaining of the sections with the Ki67 antibody. Diaminobenzidine was used as chromogen. The sections were incubated with the antibodies overnight at room temperature. Before immunostaining, the sections were microwave treated for $2 \times 5 \mathrm{~min}$ at $750 \mathrm{~W}$ using Tris buffer saline $(\mathrm{pH}$ $8.0)$ as retrieval solution.

The primary SSTRs and DR2 antibodies were polyclonal rabbit. The antibodies for the SSTRs were from Gramsch Laboratories: SSTR1 (SS-840, dilution 1:5,000); SSTR2A (SS-800, 1:5,000); SSTR3 (SS-850, 1:5,000); SSTR4 (SS-880, 1:100), and SSTR5 (SS$890,1: 5,000)$. The DR2 antibody (NLS1403, 1:750) was purchased from Novus Biologicals. In 115 of the primary LCs and in all PDECs, immunostaining was applied with the novel monoclonal rabbit anti-SSTR2A antibody, UMB-1 (1:200; Epitomics Inc.). Four primaries and all the specimens from lymph node or distant metastases were excluded due to insufficient tissue material. The Ki67 antibody used for the immunostaining of the tumor specimens was mouse monoclonal from Dako (Clone MIB-1, M7240, dilution 1:200).

\section{Calculation of Immunoreactive Cells}

In consecutive immunostained sections, the percentages of SSTR and DR2 immunoreactive cells were estimated by light microscopy at a magnification of $\times 400$ using a square grid in one of the oculars. At least five randomly selected areas were examined; in smaller lesions the whole of the neoplastic tissue.

Tumors were considered 'positive' if a membrane pattern was observed in $>10 \%$ of the tumor cells (a threshold shown to comply with autoradiography results) [34] and/or when cytoplasmic immunostaining was found in the majority $(>50 \%)$ of the tumor cells. In addition, the localization of receptor expression was assessed quantitatively with the scoring system proposed by Volante et al. [35] as follows. Score 1 (S1): pure cytoplasmic immunoreactivity; score 2 (S2): a minority tumor cell population showed membranous immunoreactivity in $<50 \%$ of the cell circumference, and score 3 (S3): a majority tumor cell population revealed membranous immunoreactivity in over $50 \%$ of the circumference.

One investigator (L.G.) categorized the tumors into TCs, ACs and PDECs as well as determined the rate of cell proliferation by calculating the Ki67 LI. Mitoses were counted on hematoxylin and eosin-stained slides at $40 \mathrm{HPF}$. The Ki67 LI was assessed in at least 2,000 tumor cells in areas where the highest nuclear labeling was observed (hot spots). The LI was calculated as the percentage of Ki67 immunoreactive cells. The analysis of the SSTRs and DR2 immunostainings was done by two investigators (L.G. and A.V.T.), and when there was discordance a post-review unanimous decision was made.

\section{Semiquantitative RT-PCR Analysis}

In a subset of $20 \mathrm{LCs}$, the five SSTRs and DR2 gene transcripts were analyzed using semiquantitative RT-PCR. Total RNA extraction and subsequent cDNA synthesis with reverse transcription were performed using standard techniques. Amplification of cDNAs was achieved using ready-to-use Long-Range PCR Nucleotide Mix (Roche Diagnostics Corp., Indianapolis, Ind., USA) and appropriate temperature programs on a MJ Thermocycler (Bio$\mathrm{Rad})$. The data were normalized to glyceraldehyde 3-phosphate dehydrogenase (GAPDH) levels which served as internal control. The primer sequences for SSTR1, SSTR2A, SSTR3, SSTR4, SSTR5, DR2, and GAPDH (control gene) are listed in online supplementary table 1 (see www.karger.com/doi/10.1159/000381061).

\section{Statistical Analysis}

Tumors were stratified according to their size (largest dimension): $\leq 3$ and $>3 \mathrm{~cm}$. This cutoff point was selected according to the TNM classification system proposed by the American Joint Committee on Cancer as it is the limit between T1 and T2 tumors (AJCC cancer staging manual ed 7,2010$)$. For nominal data, the $\chi^{2}$ test was used. Cohen's kappa coefficient was used to assess the concordance between data and Spearman's rho $\left(r_{s}\right)$ coefficient to indicate correlation among ordinal data. The level of statistical significance was set to 0.05. Calculations were performed using the Statistical Package for Social Sciences V.13.0 software (SPSS Inc., Chicago, Ill., USA).

The research protocol was reviewed and approved by the local research ethics boards (Uppsala University Hospital, Uppsala, Sweden, and University of Athens Medical School, Athens, Greece). 


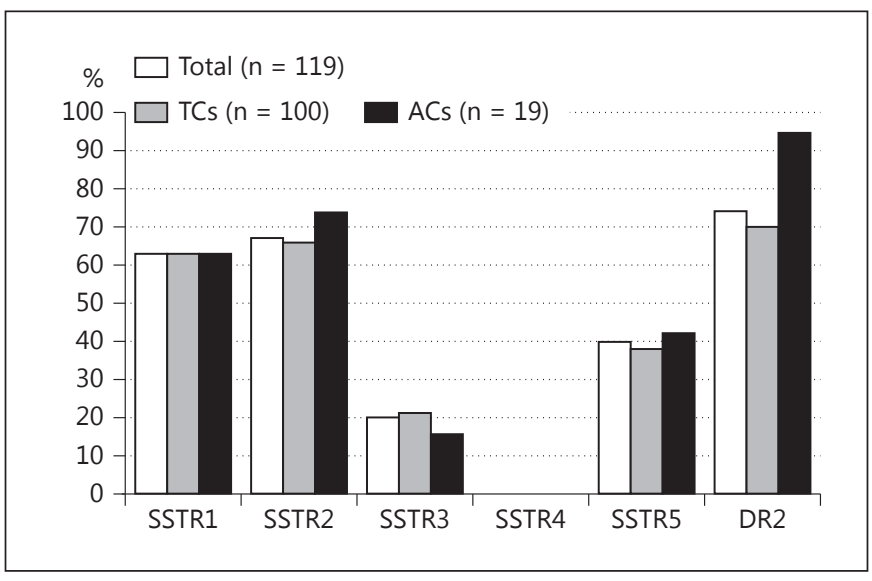

Fig. 1. Relative incidence of expression of the five SSTR subtypes and DR2 in TCs and ACs. SSTR2A results were obtained by the SS-800 antibody provided by Gramsch.

\section{Results}

\section{Controls}

Immunostaining with the antibodies against the five SSTR subtypes revealed distinct immunoreactive cells in the pancreatic islets. Similarly, positive cells were observed in the normal adenohypophysis tissue and pituitary adenomas when immunostained with the anti-DR2 antibody. No immunoreactivity was seen after the omission of the primary antiserum in question after its replacement by nonimmune serum or after the neutralization test.

\section{Immunohistochemistry and Statistical Analysis}

The vast majority of the tumor cells in the LCs expressed chromogranin A and synaptophysin. For all the SSTRs examined, positive tumor cells lying at the periphery had a tendency to express a membranous immunostaining pattern with a stronger intensity than those in the central part of the specimen. SSTR2A was the receptor most frequently expressed as it was detected in 90 cases (76\%) by using the SS-800 antibody and in 80 cases $(67 \%)$ by using the UMB-1 (mean 72\%), followed by SSTR1 (75 cases, 63\%), SSTR5 (48 cases, 40\%) and SSTR3 (24 cases, $20 \%)$; SSTR4 was not detected in any of the tumors. Overall, 99 out of 119 tumors (83\%) were positive for at least one SSTR subtype. DR2 was detected in 88 tumors (74\%). No significant difference was observed in the expression of any SSTR subtype between TCs and ACs, whereas DR2 was expressed more frequently in ACs ( 95 vs. $70 \%, \mathrm{p}=$ 0.017; fig. 1).
Regarding SSTR2A, the use of UMB-1 antibody revealed more tumor cells with membrane immunostaining pattern and with less cytoplasmic localization compared to the SS-800 antibody (fig. 2). In 35 cases, the immunostaining quality was improved in comparison to SS- 800 as 12 tumors were reclassified as S2 and 23 tumors as S3. Conversely, 17 tumors were reconciled as negative with the UMB-1. However, when the two antibodies were compared to the RT-PCR and SRS results, the SS- 800 performed better compared to the UMB-1 antibody (88 vs. $75 \%$ concordance and 90 vs. $71 \%$ concordance, respectively). Consequently, the results obtained with both antibodies were considered acceptable and both were reported unless stated otherwise.

Assessment of the receptor localization with the scoring system proposed by Volante et al. [35] revealed that the immunostaining pattern of SSTR1, SSTR 3 and SSTR5 was mainly cytoplasmic [(S1: $65 \%$ vs. S2: $34 \%$ vs. S3: $1 \%)$, (S1: $88 \%$ vs. $S 2: 8 \%$ vs. S3: $4 \%$ ) and (S1: $91 \%$ vs. S2: $7 \%$ vs. S3: $2 \%)$, respectively]. In contrast, SSTR2A exhibited a predominantly membranous (S2 or S3) pattern (S1: 10\% vs. S2: $41 \%$ vs. S3: $49 \%$ for the UMB-1 and S1: $29 \%$ vs. S2: $46 \%$ vs. S3: $25 \%$ for the SS- 800 antibody). The expression of DR2 was exclusively cytoplasmic (S1: 100\%)

We also examined the distribution of SSTR subtypes in tumors negative for SSTR2A. Among 29 tumors negative to the SS-800 antibody, 14 (48\%) expressed another SSTR. The corresponding figures were 10 (35\%), 2 (11\%) and $2(11 \%)$ for SSTR1, SSTR3 and SSTR5, respectively. Among 39 tumors negative to the UMB-1 antibody, 29 (74\%) in total were positive for SSTR1, SSTR3 or SSTR5 analyzed for each receptor as $17(44 \%), 5(13 \%)$ or 7 (18\%), respectively.

SSTR2A, SSTR3 and SSTR5 exhibited selective immunostaining in the tumoral and nontumoral fibrovascular

Fig. 2. LCs immunostained for the five SSTR subtypes and DR2. A SSTR1: predominantly cytoplasmic and partially membranous immunostaining in the minority of the tumor cells (S2 according to Volante et al. [35]). B1 SSTR2A (SS-800 antibody): circumferential membrane immunostaining in the majority of the tumor cells (S3 according to Volante et al. [35]), faint cytoplasmic staining is also observed. B2 SSTR2A (UMB1 antibody): circumferential membrane immunostaining (S3), while cytoplasmic staining is almost absent. This photograph is taken from the same area of the same tumor as in B1. C SSTR3: S3 according to Volante et al. [35] and intense immunoreactivity at the fibrovascular stroma. D SSTR4 was nonimmunoreactive. E SSTR5: immunohistochemical pattern as in S2. F DR2: cytoplasmic immunostaining in virtually all tumor cells. Insets in each panel depict the neutralization test for the corresponding receptor. Scale bars $=100 \mu \mathrm{m}$.

(For figure see next page.) 

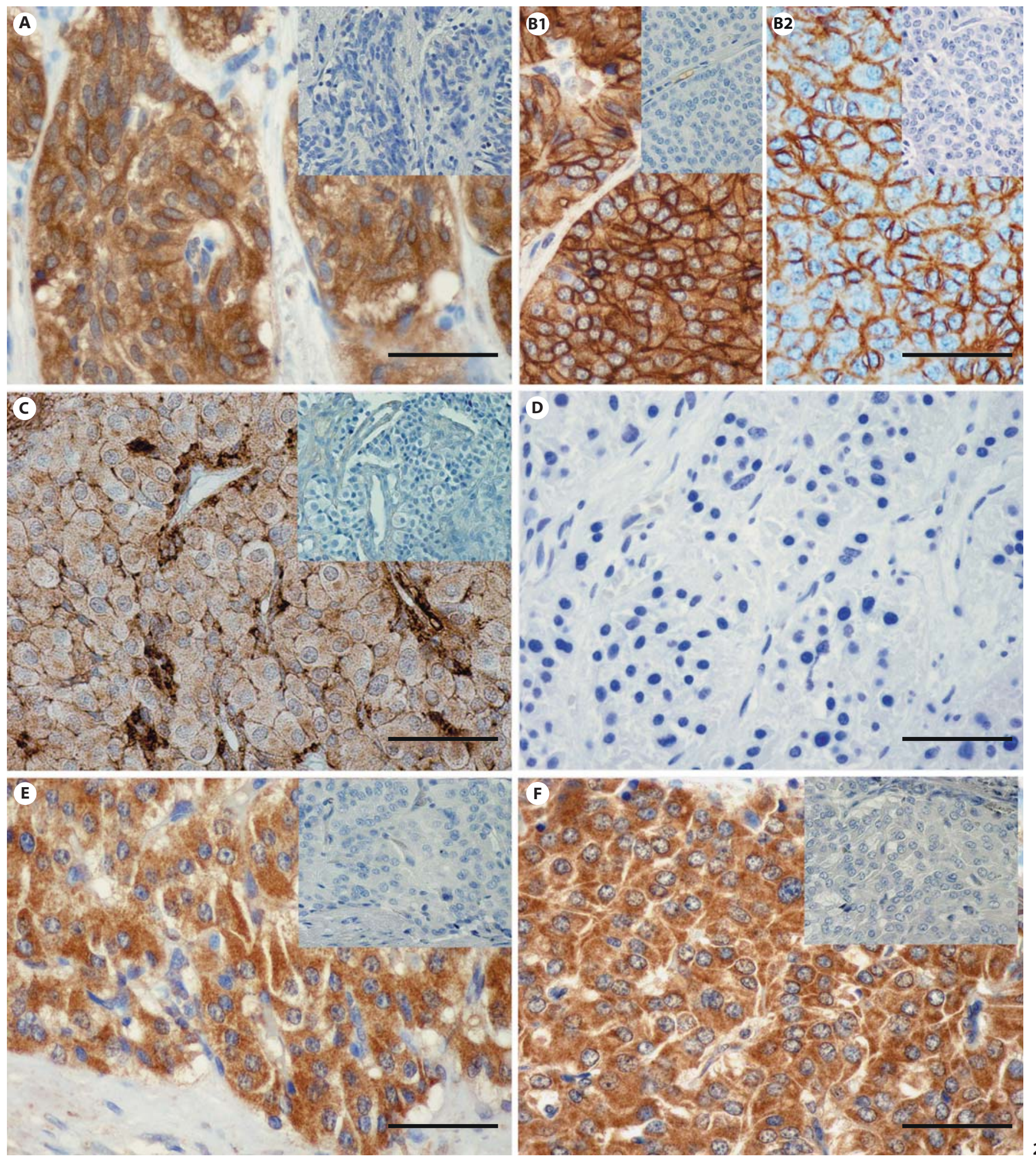


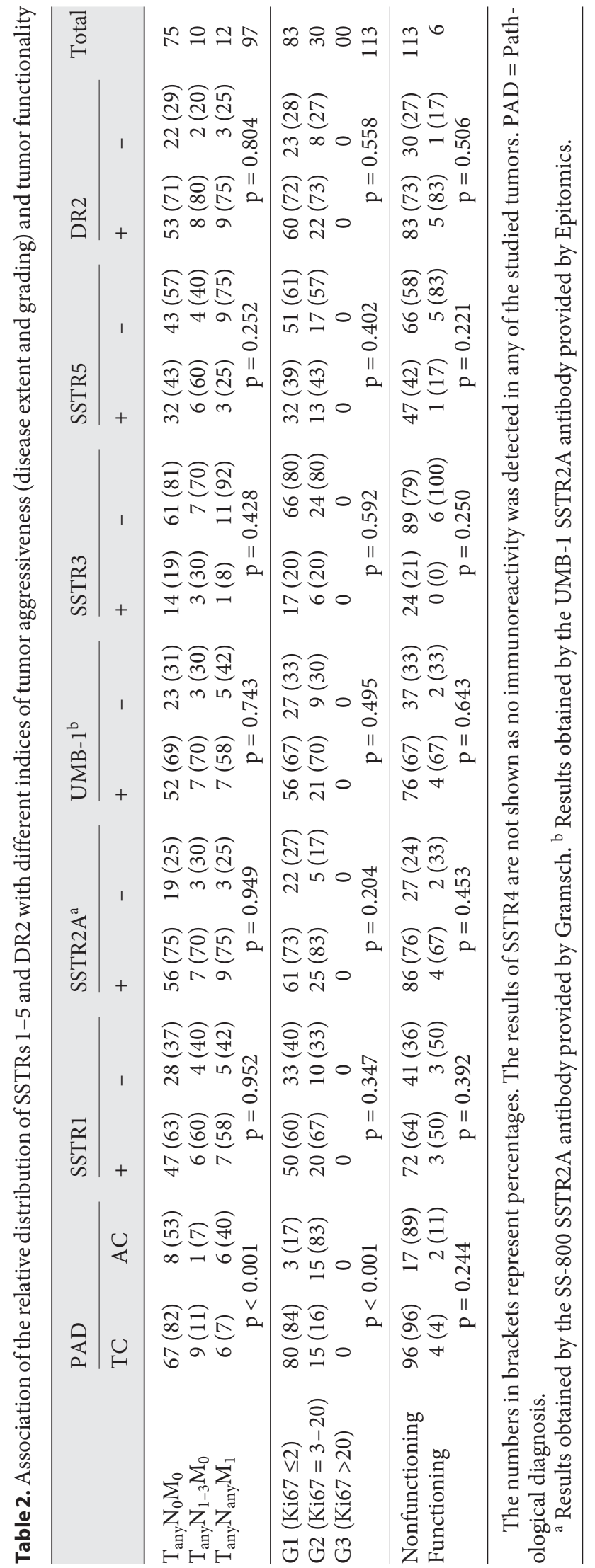

stroma in the majority of cases with variable extent. Typical examples are depicted in figure 2.

In LCNECs, SSTR expression was occasionally observed at the minority of cells, concerning exclusively SSTR1 and SSTR2A and the intensity was weaker than that observed in LCs. Regarding SCLCs, none of the studied tumors expressed any of the SSTRs. Overall, immunoreactivity for DR2 was absent in all PDECs studied. PDECs had a Ki67 LI higher than 20\% as expected.

Co-expression of DR2 with SSTR2A was observed in 75 cases $(63 \%)$ for the SS-800 and 64 (54\%) for the UMB1 antibody (mean: 59\%). The relevant scores for SSTR1, SSTR3 and SSTR5 (Gramsch antibodies), were 67 (56\%), $22(19 \%)$ and 44 (37\%), respectively. No significant difference was observed in receptor co-expression between TCs and ACs.

Furthermore, the possible association between the expression of SSTRs and DR2 with tumor aggressiveness was assessed. Initially, the tumors were stratified according to their size: 96 tumors were $\leq 3 \mathrm{~cm}$, whereas $23 \mathrm{tu}$ mors were $>3 \mathrm{~cm}$. Moreover, patients were grouped according to their disease extent. In 75 patients, the tumor was confined to lung tissue $\left(\mathrm{T}_{\text {any }} \mathrm{N}_{0} \mathrm{M}_{0}\right)$, in 10 , there was lymph node involvement $\left(\mathrm{T}_{\text {any }} \mathrm{N}_{1-3} \mathrm{M}_{0}\right)$, and in 12 , distant metastases were present $\left(\mathrm{T}_{\text {any }} \mathrm{N}_{\text {any }} \mathrm{M}_{1}\right)$. In 9 patients, data regarding disease extent were not available. No significant difference was found in the distribution of SSTR 1-5 and DR2 compared to any of these parameters. Similar results were obtained when comparing the receptor expression between functioning and nonfunctioning tumors (table 2).

Finally, the tumors were classified according to the Ki67 LI based on the grading criteria proposed by ENETS for gastroenteropancreatic NETs [36]. Of the studied tumors, $83(73 \%)$ were G1 (Ki67 LI $\leq 2 \%)$ and $30(27 \%)$ were G2 (Ki67 LI 3-20\%). None of the well-differentiated tumors proved to be G3 (Ki67 LI >20\%), whereas in 6 tumors immunostaining for Ki67 was not performed due to insufficient material. The proportion of G2 tumors was significantly higher among ACs compared to TCs (83 vs. $16 \%, \mathrm{p}<0.001)$; however, no significant difference was found regarding the distribution of any of the SSTRs or DR2 between G1 and G2 tumors (table 2). In the above comparisons, the expression of SSTR2A was studied separately by using either the SS- 800 antibody or the UMB-1 antibody; however the results were similar regardless of the antibody used.

The receptor expression was also evaluated in the 17 metastatic lesions (exclusively Gramsch antibodies available) with the following findings: SSTR1: 82\%, SSTR2A: 
Table 3. Contingency table summarizing the expression scores of SSTRs $1-5$ and DR 2 among metastatic lesions in comparison to their corresponding primary tumors

\begin{tabular}{|c|c|c|c|c|c|c|c|c|c|c|c|c|}
\hline \multirow{3}{*}{$\begin{array}{l}\text { Primary } \\
\text { Tumors }\end{array}$} & \multicolumn{12}{|c|}{ Metastases } \\
\hline & \multicolumn{2}{|c|}{ SSTR1 } & \multicolumn{2}{|c|}{ SSTR2A } & \multicolumn{2}{|c|}{ SSTR3 } & \multicolumn{2}{|c|}{ SSTR4 } & \multicolumn{2}{|c|}{ SSTR5 } & \multicolumn{2}{|c|}{ DR2 } \\
\hline & + & - & + & - & + & - & + & - & + & - & + & - \\
\hline Positive expression & 11 & 3 & 14 & 0 & 3 & 3 & 0 & 0 & 8 & 2 & 10 & 2 \\
\hline No expression & 0 & 3 & 2 & 1 & 1 & 10 & 0 & 17 & 0 & 7 & 5 & 0 \\
\hline
\end{tabular}

SSTR2A immunostaining available only with the Gramsch SS-800 antibody in all the metastases. Positive and negative expression at the metastatic lesions is denoted by the signs + and -, respectively.

82\%, SSTR3: 35\%, SSTR4: 0\%, SSTR5: 59\% and DR2: $71 \%$. Concordance between metastatic lesions and the corresponding primary tumors was found for SSTR1 in 14 cases $(82 \%)$, for SSTR2A in 15 (88\%), for SSTR3 in 13 (76\%), for SSTR5 in 15 (88\%) and for DR2 in 10 (59\%) cases (table 3). No significant difference was observed when lymph node and distant metastases were evaluated separately.

\section{Comparison to SRS Data}

The presence of concordance between SRS and IHC findings was assessed for SSTR2A, SSTR3 and SSTR5 in 30 tumors (18 primaries with their corresponding metastases) (table 4). This proved to be satisfying only for SSTR2A when assessed by the SS- 800 antibody ( $90 \%$ concordance $-k=0.62, \mathrm{p}<0,001)$. The concordance rates for SSTR3 and SSTR5 were 37\% $(k=-0.22)$ and 50\% $(k=0.18)$, respectively. The SRS uptake reported according to the KS score correlated positively to the IHC score proposed by Volante et al. [35] for SSTR2A $\left(r_{s} 0.586, \mathrm{p}=\right.$ $0.02)$; thus, tumors with membranous SSTR2A expression exhibited higher uptake. In particular, 6/10 tumors with clear tumor uptake $(K S \geq 2)$ showed membranous SSTR2A immunostaining (S2 and S3), while the remaining 4 showed a cytoplasmic immunostaining pattern (S1). Moreover, all 10 tumors with faint tumor uptake showed cytoplasmic immunostaining (S1). Finally, 3/6 tumors with no tracer uptake were negative for SSTR2A, whereas the remaining 3 had positive SSTR2A immunostaining. The relevant results for SSTR2A were inferior after using the UMB-1 antibody ( $71 \%$ concordance $-k=0.38$ ), and the correlation with KS was less strong $\left(r_{s} 0.492, \mathrm{p}=0.15\right)$.

Somatostatin and Dopamine Receptors in Lung Carcinoids
Detection of SSTR2A and DR2 Gene Transcripts in

LCs

In a subset of $20 \mathrm{LCs}$, gene transcripts of somatostatin and DRs were analyzed using semiquantitative RT-PCR. Satisfactory mRNA was extracted from 11 cases, and GAPDH (control gene) was amplifiable in 8 cases. Following normalization to GAPDH, a proportion of LCs showed variable amplification of gene transcripts of SSTR1, SSTR2A, SSTR3, SSTR5 and DR2 indicating increased transcription of the genes (fig. 3). The relative incidence of the receptors' mRNA expression was 88,88 , $12.5,63$ and $75 \%$, respectively. A concordance with IHC results for SSTR1, SSTR2A, SSTR3, SSTR5 and DR2 was observed in 63,88 (75\% for UMB-1), 88, 50 and $88 \%$, respectively. All samples tested by RT-PCR were negative for amplification of the SSTR4 gene transcript (table 5).

\section{Discussion}

In the present study, we evaluated the expression of SSTRs 1-5 and DR2 in a large series of LCs and in 20 lung PDECs. A relatively high incidence of SSTR2A (72\%) and SSTR1 (63\%) expression was observed, and to a lesser extent of SSTR5 (40\%) and SSTR3 (20\%), whereas SSTR4 was not expressed in any of the specimens studied. These findings are in line with the results reported in previous studies evaluating IHC, autoradiography, in situ hybridization and RT-PCR findings in LCs, which have shown a relative expression of SSTR1 in $60-72 \%$, of SSTR2A in $49-96 \%$, of SSTR3 in $4-40 \%$, of SSTR 5 in $14-60 \%$ and no SSTR4 expression [15, 18-21]. Recently, Tsuta et al. [22] have studied immunohistochemically the differential expression of SSTRs 1-5 in 68 LCs (57 TCs and 11 ACs; us- 
Table 4. Patients with available SSTR imaging data

\begin{tabular}{|c|c|c|c|c|c|c|c|c|c|c|}
\hline \multirow[t]{2}{*}{$\mathrm{S} / \mathrm{N}$} & \multirow[t]{2}{*}{ Material } & \multirow[t]{2}{*}{ PAD } & \multirow[t]{2}{*}{ SRS } & \multirow[t]{2}{*}{ KS } & \multicolumn{4}{|c|}{ SSTR2A } & \multirow[t]{2}{*}{ SSTR3 } & \multirow[t]{2}{*}{ SSTR5 } \\
\hline & & & & & SS-800 & $\begin{array}{l}\text { SS-800 } \\
\text { score }^{\text {a }}\end{array}$ & UMB-1 & $\begin{array}{l}\text { UMB-1 } \\
\text { score }^{\mathrm{a}}\end{array}$ & & \\
\hline $1 \mathrm{a}$ & PRIM & $\mathrm{AC}$ & + & 2 & + & 1 & NA & NA & - & - \\
\hline $1 b$ & LNM & $\mathrm{AC}$ & + & 2 & + & 1 & NA & NA & - & - \\
\hline 2 & PRIM & $\mathrm{TC}$ & + & 3 & + & 2 & + & 3 & + & + \\
\hline 3 & PRIM & $\mathrm{TC}$ & - & 0 & - & 0 & - & 0 & - & - \\
\hline 4 & PRIM & $\mathrm{TC}$ & - & 0 & - & 0 & - & 0 & - & - \\
\hline 5 & PRIM & TC & + & 1 & + & 1 & - & 0 & - & - \\
\hline 6 & PRIM & $\mathrm{TC}$ & + & 1 & + & 1 & + & 1 & - & - \\
\hline $7 \mathrm{a}$ & PRIM & $\mathrm{AC}$ & + & 1 & + & 1 & + & 3 & - & - \\
\hline $7 \mathrm{~b}$ & HEP & $\mathrm{AC}$ & + & 3 & + & 3 & + & 3 & - & + \\
\hline $8 \mathrm{a}$ & PRIM & $\mathrm{TC}$ & + & 1 & + & 1 & - & 0 & - & + \\
\hline $8 b$ & HEP & $\mathrm{TC}$ & + & 2 & + & 1 & - & 0 & - & + \\
\hline $8 c$ & $\mathrm{ADR}$ & $\mathrm{TC}$ & + & 2 & + & 1 & - & 0 & - & + \\
\hline $9 a$ & PRIM & $\mathrm{TC}$ & + & 1 & + & 1 & - & 0 & - & - \\
\hline $9 b$ & HEP & $\mathrm{TC}$ & + & 4 & + & 2 & + & 2 & - & - \\
\hline $9 c$ & LNM & $\mathrm{TC}$ & + & 1 & + & 1 & + & 2 & - & - \\
\hline $9 \mathrm{~d}$ & LNM & $\mathrm{TC}$ & - & 0 & + & 3 & + & 3 & + & + \\
\hline 10 & PRIM & TC & + & 3 & + & 3 & + & 2 & - & - \\
\hline 11 & PRIM & TC & - & 0 & - & 0 & - & 0 & - & - \\
\hline 12 & PRIM & TC & + & 3 & + & 3 & + & 3 & + & + \\
\hline $13 a$ & PRIM & TC & - & 0 & + & 1 & - & 0 & - & - \\
\hline $13 b$ & PRIM & TC & - & 0 & + & 1 & - & 0 & + & - \\
\hline 14 & PRIM & TC & + & 1 & + & 1 & + & 2 & - & + \\
\hline $15 a$ & PRIM & $\mathrm{AC}$ & + & $\mathrm{PET}+{ }^{\mathrm{b}}$ & + & 3 & + & 3 & + & + \\
\hline $15 b$ & HEP & $\mathrm{AC}$ & + & PET+ & + & 3 & + & 3 & + & + \\
\hline $16 a$ & PRIM & $\mathrm{TC}$ & + & PET+ & + & 1 & + & 2 & + & - \\
\hline $16 b$ & LNM & $\mathrm{TC}$ & + & $\mathrm{PET}+$ & + & 1 & + & 3 & - & - \\
\hline $17 a$ & PRIM & $\mathrm{TC}$ & + & 1 & + & 1 & - & 0 & - & - \\
\hline $17 b$ & LNM & $\mathrm{TC}$ & + & 1 & + & 1 & - & 0 & + & - \\
\hline $18 \mathrm{a}$ & LNM & $\mathrm{TC}$ & + & 1 & + & 1 & + & 2 & - & - \\
\hline $18 b$ & LNM & $\mathrm{TC}$ & + & 2 & + & 3 & + & 3 & + & + \\
\hline
\end{tabular}

Correlation with immunohistochemical findings. Specimens with the same serial number $(\mathrm{S} / \mathrm{N})$ were obtained from the same patient. PAD = Pathological diagnosis; PRIM = primary tumor; $\mathrm{LNM}=$ lymph node metastasis; $\mathrm{HEP}=$ liver metastasis; $\mathrm{ADR}=$ adrenal metastasis.

a SSTR2A scoring according to the score proposed by Volante et al. [35]. ${ }^{68}$ Ga-DOTATOC positron emission tomography positive tumors with SUV max 17.

ing the antibodies provided by Gramsch) and the corresponding results were $83,96,47,4$ and $0 \%$ for SSTRs $1-5$, respectively; however, they applied a different scoring system. Regarding DR2, the expression frequency has been reported to range between 75 and $100 \%[31,32]$. We have demonstrated a similarly high incidence $(74 \%)$ of DR2 expression and have additionally documented the co-expression of DR2 with different SSTRs in more than half of the investigated tumors.
No difference was observed regarding SSTR expression between TCs and ACs, whereas the expression of DR2 was more avid in ACs. These findings are not completely in line with the current notion that receptor expression seems to decrease with increasing tumoral dedifferentiation. By contrast, the findings in PDECs complied with this statement, since the expression of all SSTRs and DR2 was negligible in these tumors [19]. These results may favor the opinion of several authors that LCs and lung PDECs form two separate groups of tumors with different 
Table 5. RT-PCR amplification results and the corresponding IHC receptor expression as demonstrated by means of IHC shown as positive (+)/negative (-) values as well as agreement scores between the two methods

\begin{tabular}{|c|c|c|c|c|c|c|c|c|c|c|c|}
\hline \multicolumn{12}{|c|}{ RT-PCR Amplification } \\
\hline \multicolumn{2}{|c|}{ SSTR1 } & \multicolumn{2}{|c|}{$\begin{array}{l}\text { SSTR2A } \\
(\mathrm{UMB}-1)^{\mathrm{a}}\end{array}$} & \multicolumn{2}{|c|}{ SSTR3 } & \multicolumn{2}{|c|}{ SSTR4 } & \multicolumn{2}{|c|}{ SSTR5 } & \multicolumn{2}{|c|}{ DR2 } \\
\hline+ & - & + & - & + & - & + & - & + & - & + & - \\
\hline
\end{tabular}

\begin{tabular}{cllllllllllll}
$\begin{array}{c}\text { IHC expression } \\
\text { Positive }\end{array}$ & 4 & 0 & $6(5)$ & $0(0)$ & 0 & 0 & 0 & 0 & 1 & 0 & 5 & 0 \\
None & 3 & 1 & $1(2)$ & $1(1)$ & 1 & 7 & 0 & 8 & 4 & 3 & 1 & 2 \\
\hline Agreement & $63 \%$ & $\begin{array}{l}88 \%(75 \%) \\
(\mathrm{k}=0.60)\end{array}$ & $88 \%^{\mathrm{b}}$ & & $100 \%^{\mathrm{b}}$ & & $\begin{array}{l}50 \% \\
(\mathrm{k}=0.16)\end{array}$ & $\begin{array}{l}88 \% \\
(\mathrm{k}=0.72)\end{array}$ \\
\hline
\end{tabular}

a The results in brackets refer to the UMB-1 antibody.

${ }^{\mathrm{b}} \mathrm{k}$ was not computed because SSTR3-IHC and SSTR4-IHC is a constant.

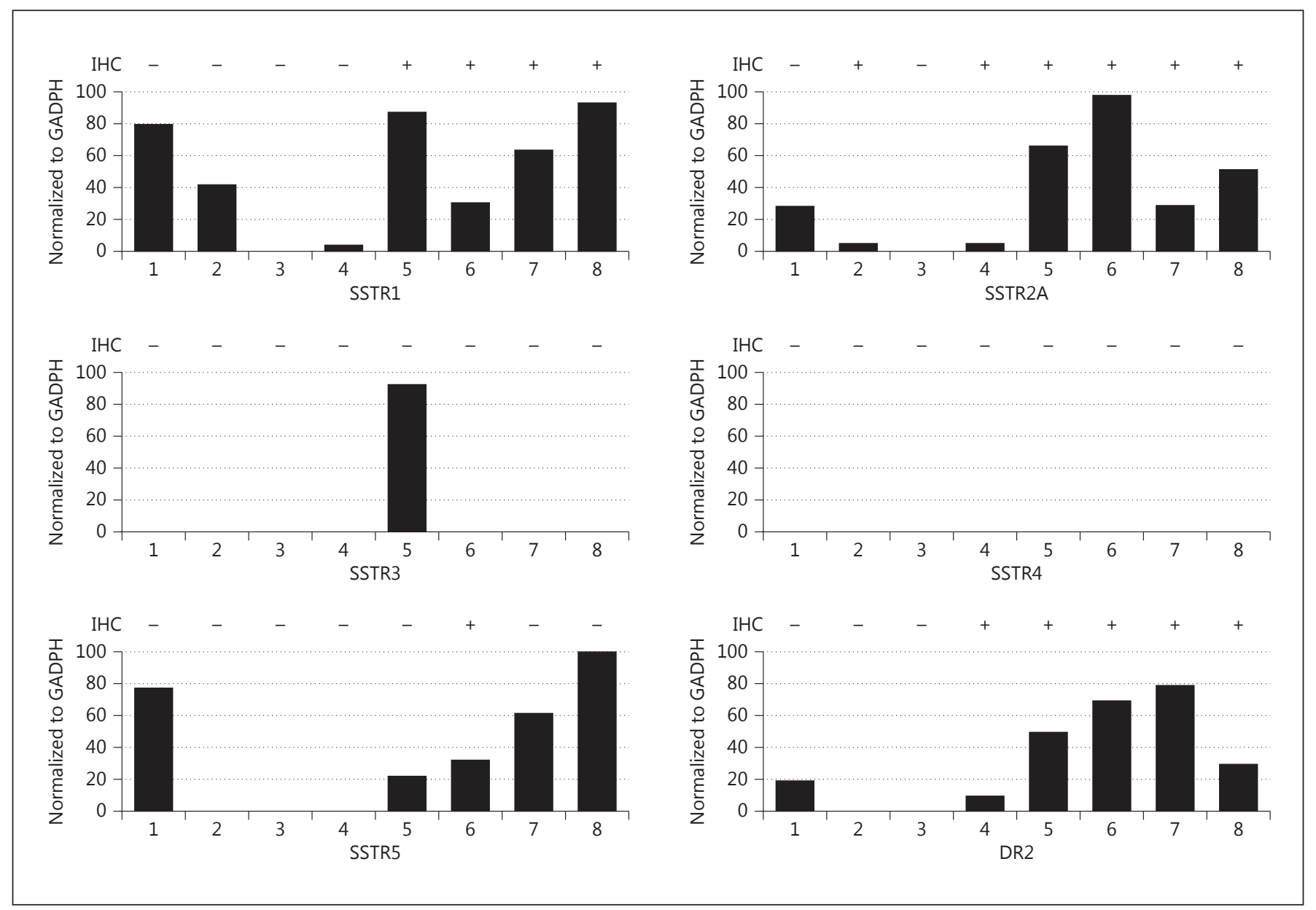

Fig. 3. Detection of SSTRs $1-5$ and DR2 by semiquantitative RTPCR in LCs. The bars represent the level of amplification of the receptor gene products after normalization to GADPH levels. The symbols + or - above the bars stand for positive or negative immunohistochemical expression, respectively. A group of 8 cases is shown. 
properties and variable behavior, rather than comprising a continuum with TCs and SCLCs representing the two extremes and ACs with LCNECs lying in the middle.

The immunoreactivity of SSTRs and DR2 was predominantly cytoplasmic, apart from SSTR2A that was mainly localized on the cell membrane. The clinical significance of cytoplasmic immunostaining was further studied by comparing the expression of SSTR2A by using two different antibodies, one polyclonal (SS-800) and one monoclonal (UMB-1). The relative expression frequencies were comparable (76 vs. $67 \%$ ), and UMB-1 was associated with a predominantly membranic pattern with less background immunostaining. However, the results obtained by SS- 800 correlated better with those obtained by RT-PCR and SRS. In this case, membrane expression of SSTR2A was related to higher SRS uptake ( $\mathrm{KS} \geq 2)$; nevertheless, uptake was also observed among tumors with cytoplasmic SSTR2A expression, though this was less strong (KS 1). The presence of receptors in tumors with cytoplasmic staining was confirmed by semiquantitative RT-PCR, and a possible explanation for this is that receptor protein may accumulate in the cytoplasm shortly after its biosynthesis or after internalization as part of receptor metabolism $[37,38]$. This issue may also be of importance regarding DR2 and particularly the way we evaluate its co-expression with SSTR subtypes. The internalization of DR2 may prevent receptor dimerization, with SSTRs located on the membrane, which is essential for the effects of chimeric compounds to take place [28].

Among SSTRs, only SSTR2A expression agreed substantially with the SRS findings, a result that was predictable due to the pharmacokinetic properties of the applied tracer (DTPA-octreotide). Moreover, it is of interest that half of the tumors negative to SRS exhibited various expressions of SSTRs immunohistochemically, suggesting that IHC could be an additional and potentially more sensitive predictive marker compared to SRS before applying therapies based on SAs.

An inadvertent finding was the expression of SSTR3 at the tumoral and nontumoral fibrovascular stroma. Previous studies have demonstrated the expression of SSTR2A and SSTR5 in fibrovascular stroma of nontumoral tissues (endothelial and immune cells) [39]; however, the expression of SSTR3 is a relative novel finding. This pattern is mainly encountered in endothelial cells of rapidly proliferating vessels and it might be correlated to neoangiogenesis [40].

The substantial concordance between immunohistochemical and RT-PCR findings, regarding SSTR2A, SSTR3, SSTR4 and DR2, suggests that IHC detects reli- ably at least these receptors in LCs. In contrast, concerning SSTR1 and SSTR5, the results were not that obvious as RT-PCR demonstrated receptor expression in more tumors compared to IHC. However, this finding could be explained by post-transcription events that may not allow the expression of the genes at the protein level. Besides, RT-PCR has been reported elsewhere to be a more sensitive detecting method than IHC [19].

The assessment of receptor expression in metastatic lesions in comparison to their 'antecedent' primary tumor showed in general fair to good concordance rates regarding SSTR1, SSTR2A and SSTR3 $(k=0.57,0.45$ and 0.44 , respectively) and excellent concordance regarding SSTR5 $(k=0.77)$. In contrast, agreement was poor regarding DR2 $(k=-0.2)$. According to these results, the SSTR profile of a metastatic lesion may reflect sufficiently the corresponding profile of the primary tumor, whereas this seems not to be the case for DR2.

Currently the standard treatment of LCs is surgery, while there are not guidelines available for medical treatment. In previous studies, SAs have offered efficient symptomatic relief but an effect on tumor growth was found only in a minority of patients [41]. However, more recent studies have demonstrated the ability of SAs to control the growth of well-differentiated small-intestine NETs [42]. In addition, a beneficial antitumoral effect of novel multivalent SAs that can bind to several SSTRs has been shown in LC cell lines [10]. In the present study, SSTR2A, the major target of the currently used SAs, was undetectable in $25-33 \%$ of the studied tumors, irrespective of the antibody used (SS-800 or UMB-1). However, $50-75 \%$ of these tumors expressed at least one SSTR among SSTR1, SSTR3 and SSTR5, offering the rationale for a therapeutic trial with such multivalent analogues in poor responders to currently used SAs such as octreotide/lanreotide.

The expression of DRs in NETs may also be of therapeutic significance as the DA cabergoline has been shown to exert some effect in pancreatic NETs [43]. Furthermore, synergistic action of SAs and cabergoline has been shown in a patient with refractory Cushing's syndrome due to ectopic adrenocorticotrophin secretion by a LC [27]. Receptor heterodimerization between SSTRs and DRs has been observed [28], and novel chimeric molecules that couple both SSTRs and DR2 - such as BIM23A387 that targets SSTR2A and DR2 and BIM23A760 that targets SSTR2A, SSTR5 and DR2 - have been developed $[44,45]$. These agents show at least in vitro more potent antiproliferative effects than each component alone or in combination; thus, demonstrating that tumors co-express DR2 with different SSTRs may help to 
identify patients suitable for treatment rather than applying such expensive therapies to the whole cohort. However, a randomized study may be necessary to address this issue.

In summary, this study provides a full mapping of the five SSTR subtypes and assesses their co-expression with DR2 in LCs. Apart from SSTR2A, a high relative incidence of SSTR 1 and to a lesser extent of SSTR 5 and SSTR3 was observed. This finding and the co-expression of SSTRs and DR2 in a significant number of these tumors could provide a rationale for the possible treatment with agents that target these receptors.

\section{Acknowledgements}

The authors thank Dr. D. Papaioannou (Hygeia Hospital, Athens) for providing tissue material as part of the total patient cohort. This work was supported by the Selander Foundation and the Hellenic Endocrine Society.

\section{Disclosure Statement}

A.V.T. has received honoraria from Novartis and Ipsen, and G.K. from Novartis.

\section{References}

1 Quaedvlieg PF, Visser O, Lamers CB, Janssen-Heijen ML, Taal BG: Epidemiology and survival in patients with carcinoid disease in The Netherlands. An epidemiological study with 2,391 patients. Ann Oncol 2001;12: 1295-1300.

-2 Skuladottir H, Hirsch FR, Hansen HH, Olsen $\mathrm{JH}$ : Pulmonary neuroendocrine tumors: incidence and prognosis of histological subtypes. A population-based study in Denmark. Lung Cancer 2002;37:127-135

- 3 Travis WD, Rush W, Flieder DB, Falk R, Fleming MV, Gal AA, Koss MN: Survival analysis of 200 pulmonary neuroendocrine tumors with clarification of criteria for atypical carcinoid and its separation from typical carcinoid. Am J Surg Pathol 1998;22:934-944.

4 Travis WD; World Health Organization; International Agency for Research on Cancer; International Association for the Study of Lung Cancer; International Academy of Pathology: Pathology and Genetics of Tumours of the Lung, Pleura, Thymus and Heart. Oxford, Oxford University Press, 2004.

5 Eriksson B, Janson ET, Bax ND, Mignon M, Morant R, Opolon P, Rougier P, Oberg KE: The use of new somatostatin analogues, lanreotide and octastatin, in neuroendocrine gastro-intestinal tumours. Digestion 1996; 57(suppl 1):77-80.

-6 Lamberts SW, Reubi JC, Krenning EP: Somatostatin receptor imaging in the diagnosis and treatment of neuroendocrine tumors. J Steroid Biochem Mol Biol 1992;43:185-188.

7 Weckbecker G, Lewis I, Albert R, Schmid HA Hoyer D, Bruns C: Opportunities in somatostatin research: biological, chemical and therapeutic aspects. Nat Rev Drug Discov 2003;2:999-1017.

8 Fjallskog ML, Ludvigsen E, Stridsberg M, Oberg K, Eriksson B, Janson ET: Expression of somatostatin receptor subtypes 1-5 in tumor tissue and intratumoral vessels in malignant endocrine pancreatic tumors. Med Oncol 2003;20:59-67.
-9 Gugger M, Waser B, Kappeler A, Schonbrunn A, Reubi JC: Immunohistochemical localization of somatostatin receptor sst $2 \mathrm{~A}$ in human gut and lung tissue: possible implications for physiology and carcinogenesis. Ann NY Acad Sci 2004;1014:132-136.

10 Ono K, Suzuki T, Miki Y, Taniyama Y, Nakamura Y, Noda Y, Watanabe M, Sasano H: Somatostatin receptor subtypes in human nonfunctioning neuroendocrine tumors and effects of somatostatin analogue SOM230 on cell proliferation in cell line NCI-H727. Anticancer Res 2007;27:2231-2239.

-11 Diakatou E, Kaltsas G, Tzivras M, Kanakis G, Papaliodi E, Kontogeorgos G: Somatostatin and dopamine receptor profile of gastroenteropancreatic neuroendocrine tumors: an immunohistochemical study. Endocr Pathol 2010;22:24-30.

12 Volante M, Bozzalla-Cassione F, Papotti M: Somatostatin receptors and their interest in diagnostic pathology. Endocr Pathol 2004;15: 275-291.

13 Wulbrand U, Wied M, Zofel P, Goke B, Arnold R, Fehmann H: Growth factor receptor expression in human gastroenteropancreatic neuroendocrine tumours. Eur J Clin Invest 1998;28:1038-1049.

14 Janson ET, Stridsberg M, Gobl A, Westlin JE, Oberg K: Determination of somatostatin receptor subtype 2 in carcinoid tumors by immunohistochemical investigation with somatostatin receptor subtype 2 antibodies. Cancer Res 1998;58:2375-2378.

15 Kimura N, Pilichowska M, Date F, Kimura I, Schindler M: Immunohistochemical expression of somatostatin type $2 \mathrm{~A}$ receptor in neuroendocrine tumors. Clin Cancer Res 1999;5: 3483-3487.

16 Kulaksiz H, Eissele R, Rossler D, Schulz S, Hollt V, Cetin Y, Arnold R: Identification of somatostatin receptor subtypes $1,2 \mathrm{~A}, 3$, and 5 in neuroendocrine tumours with subtype specific antibodies. Gut 2002;50:52-60.
17 Papotti M, Bongiovanni M, Volante M, Allia E, Landolfi S, Helboe L, Schindler M, Cole SL, Bussolati G: Expression of somatostatin receptor types 1-5 in 81 cases of gastrointestinal and pancreatic endocrine tumors. A correlative immunohistochemical and reverse-transcriptase polymerase chain reaction analysis. Virchows Arch 2002;440:461-475.

18 Reubi JC, Waser B: Concomitant expression of several peptide receptors in neuroendocrine tumours: molecular basis for in vivo multireceptor tumour targeting. Eur J Nucl Med Mol Imaging 2003;30:781-793.

19 Papotti M, Croce S, Bello M, Bongiovanni M, Allia E, Schindler M, Bussolati G: Expression of somatostatin receptor types 2,3 and 5 in biopsies and surgical specimens of human lung tumours. Correlation with preoperative octreotide scintigraphy. Virchows Arch 2001; 439:787-797.

20 Righi L, Volante M, Tavaglione V, Bille A, Daniele L, Angusti T, Inzani F, Pelosi G, Rindi G, Papotti M: Somatostatin receptor tissue distribution in lung neuroendocrine tumours: a clinicopathologic and immunohistochemical study of 218 'clinically aggressive' cases. Ann Oncol 2010;21:548-555.

-21 Fassan M, Rea F, Clemente R, Rizzardi G, Pizzi M, Giacomelli L, Rugge M: Somatostatin receptor type 2 (SSTR2) in bronchopulmonary carcinoids. Endocr Pathol 2010;21:204-205.

-22 Tsuta K, Wistuba II, Moran CA: Differential expression of somatostatin receptors $1-5$ in neuroendocrine carcinoma of the lung. Pathol Res Pract 2012;208:470-474.

23 Giandomenico V, Cui T, Grimelius L, Oberg K, Pelosi G, Tsolakis AV: Olfactory receptor $51 \mathrm{E} 1$ as a novel target for diagnosis in somatostatin receptor-negative lung carcinoids. J Mol Endocrinol 2013;51:277-286.

24 Reubi JC, Schaer JC, Waser B, Mengod G: Expression and localization of somatostatin receptor SSTR1, SSTR2, and SSTR3 messenger RNAs in primary human tumors using in situ hybridization. Cancer Res 1994;54:3455-3459. 
25 Schmid HA: Pasireotide (SOM230): development, mechanism of action and potential applications. Mol Cell Endocrinol 2008;286: 69-74.

-26 Missale C, Nash SR, Robinson SW, Jaber M, Caron MG: Dopamine receptors: from structure to function. Physiol Rev 1998;78:189225.

27 Pivonello R, Ferone D, Lamberts SW, Colao A: Cabergoline plus lanreotide for ectopic Cushing's syndrome. N Engl J Med 2005;352: 2457-2458.

28 Rocheville M, Lange DC, Kumar U, Patel SC, Patel RC, Patel YC: Receptors for dopamine and somatostatin: formation of hetero-oligomers with enhanced functional activity. Science 2000;288:154-157.

29 Pivonello R, Ferone D, de Herder WW, Kros JM, De Caro ML, Arvigo M, Annunziato L, Lombardi G, Colao A, Hofland LJ, Lamberts SW: Dopamine receptor expression and function in corticotroph pituitary tumors. J Clin Endocrinol Metab 2004;89:2452-2462.

-30 O’Toole D, Saveanu A, Couvelard A, Gunz G, Enjalbert A, Jaquet P, Ruszniewski P, Barlier A: The analysis of quantitative expression of somatostatin and dopamine receptors in gastro-entero-pancreatic tumours opens new therapeutic strategies. Eur J Endocrinol 2006; 155:849-857.

- 31 Grossrubatscher E, Veronese S, Ciaramella PD, Pugliese R, Boniardi M, De Carlis L, Torre M, Ravini M, Gambacorta M, Loli P: High expression of dopamine receptor subtype 2 in a large series of neuroendocrine tumors. Cancer Biol Ther 2008;7:1970-1978.

- 32 Srirajaskanthan R, Watkins J, Marelli L, Khan $\mathrm{K}$, Caplin ME: Expression of somatostatin and dopamine 2 receptors in neuroendocrine tumours and the potential role for new biotherapies. Neuroendocrinology 2009;89:308-314.
33 Kwekkeboom DJ, Teunissen JJ, Bakker WH, Kooij PP, de Herder WW, Feelders RA, van Eijck CH, Esser JP, Kam BL, Krenning EP: Radiolabeled somatostatin analog [177Lu-DOTA0, Tyr3] octreotate in patients with endocrine gastroenteropancreatic tumors. J Clin Oncol 2005;23:2754-2762.

- 34 Korner M, Waser B, Schonbrunn A, Perren A, Reubi JC: Somatostatin receptor subtype 2A immunohistochemistry using a new monoclonal antibody selects tumors suitable for in vivo somatostatin receptor targeting. Am J Surg Pathol 2012;36:242-252.

35 Volante M, Brizzi MP, Faggiano A, La Rosa S, Rapa I, Ferrero A, Mansueto G, Righi L, Garancini S, Capella C, De Rosa G, Dogliotti L, Colao A, Papotti M: Somatostatin receptor type $2 \mathrm{~A}$ immunohistochemistry in neuroendocrine tumors: a proposal of scoring system correlated with somatostatin receptor scintigraphy. Mod Pathol 2007;20: 1172-1182.

36 Rindi G, Kloppel G, Couvelard A, Komminoth P, Korner M, Lopes JM, McNicol AM, Nilsson O, Perren A, Scarpa A, Scoazec JY, Wiedenmann B: TNM staging of midgut and hindgut (neuro) endocrine tumors: a consensus proposal including a grading system. Virchows Arch 2007;451:757-762.

37 de Bruin C, Feelders RA, Waaijers AM, van Koetsveld PM, Sprij-Mooij DM, Lamberts SW, Hofland LJ: Differential regulation of human dopamine D2 and somatostatin receptor subtype expression by glucocorticoids in vitro. J Mol Endocrinol 2009;42:47-56.

38 Reubi JC, Waser B, Liu Q, Laissue JA, Schonbrunn A: Subcellular distribution of somatostatin sst2A receptors in human tumors of the nervous and neuroendocrine systems: membranous versus intracellular location. J Clin Endocrinol Metab 2000;85:3882-3891.
39 Taniyama Y, Suzuki T, Mikami Y, Moriya T, Satomi S, Sasano H: Systemic distribution of somatostatin receptor subtypes in human: an immunohistochemical study. Endocr J 2005; 52:605-611.

40 Watson JC, Balster DA, Gebhardt BM, O’Dorisio TM, O’Dorisio MS, Espenan GD, Drouant GJ, Woltering EA: Growing vascular endothelial cells express somatostatin subtype 2 receptors. Br J Cancer 2001;85:266-272.

41 Granberg D, Eriksson B, Wilander E, Grimfjard P, Fjallskog ML, Oberg K, Skogseid B: Experience in treatment of metastatic pulmonary carcinoid tumors. Ann Oncol 2001;12: 1383-1391.

42 Rinke A, Muller HH, Schade-Brittinger C, Klose KJ, Barth P, Wied M, Mayer C, Aminossadati B, Pape UF, Blaker M, Harder J, Arnold C, Gress T, Arnold R; Placebo-controlled, double-blind, prospective, randomized study on the effect of octreotide LAR in the control of tumor growth in patients with metastatic neuroendocrine midgut tumors: a report from the PROMID Study Group. J Clin Oncol 2009;27:4656-4663.

43 Pathak RD, Tran TH, Burshell AL: A case of dopamine agonists inhibiting pancreatic polypeptide secretion from an islet cell tumor. J Clin Endocrinol Metab 2004;89:581-584.

44 Ferone D, Arvigo M, Semino C, Jaquet P, Saveanu A, Taylor JE, Moreau JP, Culler MD, Albertelli M, Minuto F, Barreca A: Somatostatin and dopamine receptor expression in lung carcinoma cells and effects of chimeric somatostatin-dopamine molecules on cell proliferation. Am J Physiol Endocrinol Metab 2005;289:E1044-E1050.

45 Kidd M, Drozdov I, Joseph R, Pfragner R, Culler M, Modlin I: Differential cytotoxicity of novel somatostatin and dopamine chimeric compounds on bronchopulmonary and small intestinal neuroendocrine tumor cell lines. Cancer 2008;113:690-700. 